\title{
Return to Work following Ill Health or Disability in a Public-Private Health Care Facility: A Study in South Africa
}

\author{
Rubendri Govender ${ }^{1}$, Deshini Naidoo ${ }^{2} \&$ Pragashnie Govender $^{2}$ \\ ${ }^{1}$ Assistant Director, Occupational Therapy Department, Inkosi Albert Luthuli Central Hospital, KwaZulu Natal, \\ South Africa \\ ${ }^{2}$ Discipline of Occupational Therapy, School of Health Sciences, University of KwaZulu Natal (Westville \\ Campus), South Africa \\ Correspondence: Deshini Naidoo, Discipline of Occupational Therapy, School of Health Sciences, University of \\ KwaZulu Natal (Westville Campus), South Africa. E-mail: naidoodes@ukzn.ac.za
}

Received: May 23, 2019 Accepted: June 24, 2019 Online Published: July 31, 2019

doi:10.5539/gjhs.v11n9p170 URL: https://doi.org/10.5539/gjhs.v11n9p170

\begin{abstract}
Introduction: Disability management involves is dynamic interactional strategies used to promote an individual's return to work. These strategies revolve around the person's health condition and contextual factors for example their employer and the work environment. However, there remains limited literature on the strategies used in the public healthcare sector. Objective: To explore the return to work strategies used at a public sector facility in the province of KwaZulu Natal, South Africa.
\end{abstract}

Method: A case study design, with multiple sources of data contributed towards profiling disability management strategies implemented at a central quaternary health care facility. Data collection methods included a file audit, work ability index assessments and semi-structured interviews with employees. Saturation sampling was used to recruit $\mathrm{n}=23$ employees who had been referred for occupational therapy vocational assessments over a period of 10 years. Data from the file audit were analysed using descriptive statistics and interviews were analysed using thematic analysis.

Results: Fifty six percent $(n=38)$ of the participants that were currently employed at the institution scored between 28 and 38 (moderate) on the Work Ability Index and required job realignments and reasonable accommodations within their current vocations. Twenty two percent $(n=5)$ scored 7-9 (poor) and were medically boarded or on long-term incapacity leave.

Conclusions: Occupational therapists play a significant role in disability management within public health care facilities. Return to work strategies and reasonable accommodations can improve productivity in the workplace.

Keywords: disability management, return to work, occupational therapy, vocational rehabilitation

\section{Introduction}

Employees' health and wellbeing contributes towards the human and economic development of a country (BakerMcClearn, Greasley, Dale, \& Griffith, 2010; Munir, Yarker, \& Haslam, 2008). There is evidence in the literature to suggest that many factors influence worker's health necessitating the need to develop a more proactive approach to wellness and prevention of ill health and disabilities rather than focusing on sickness (Baker-McClean et al., 2010; Munir et al., 2008; Shreuder, 2012). Sickness absence, which is defined as not attending work when scheduled due to sickness, and which may be either short-term (one to seven days), certified absence, or long term absence due to ill health or injury raises concerns (Munir et al., 2008; Shreuder, 2012). In 2013, estimated sickness absence costs for South Africa was 4.29 billion rand a year (Grobler \& Lapere, 2016). Limited research is however available on the efforts to manage or control sickness absence (Baker-McClean et al., 2010; Munir et al., 2008; Shreuder, 2012). Supervisors are considered essential in managing sick absence in terms of adjusted work tasks, transitional duties and implementing organisational policies on absenteeism (Baker-McClean et al., 2010; Munir et al., 2008; Shreuder, 2012).

The South African public sector currently does not have coordinated occupational health $(\mathrm{OH})$ services and data available on the disease profile of the South African health care workforce is scant (Burger van Eeden \& Jordan, 2008; Naidoo, Naidoo, \& Hariparsad, 2016). However, the national burden of disease of health care workers 
(HCWS) in South Africa related to non-communicable diseases (cardiovascular disease, type two diabetes, cancer, chronic lung disease, injury related disorder and depression) has significantly increased since 1994 and this could be attributed to ageing and the move from the rural areas to urban settings (Mayosi, Flisher, Lalloo, Sitas, Tollman, \& Bradshaw, 2009).

Employers face challenges in managing long-term absence as the result of an acquired disability or an impairment. Despite the variable definitions of disability, the common trends include that a disability must be long term and should be a recurring impairment, which influences the person's ability to participate in employment (Republic of South Africa, 2002). Within the workplace, disability focuses on the "effect of a disability on the individual in relation to the working environment and not on the diagnosis or the impairment" (Republic of South Africa, 2005, p.5).

The Employment Equity Act 55 of 1998 for South Africa describes disability within the context of employment as people who have a long-lasting or persistent physical or mental impairment, which significantly limits their ability to participate in the work environment or to progress in employment (Republic of South Africa, 1998). The South African Code of Good Practice on Employment of People with Disabilities (Republic of South Africa, 2002) supports this definition and further reports that impairments must last more than 12 months, limit function and must be progressive. Impairments can be physical, cognitive, mental, or emotional. Physical impairment is a partial or total loss of bodily functions or a loss of part of the body. Mental impairment is an impairment that affects a person's thought process, judgment and emotion (Republic of South Africa, 2002, Republic of South Africa, 1998). An individual can have both disabilities depending on their diagnosis. Progressive conditions are those conditions that are likely to deteriorate and worsen with time.

According to the, Employment Equity Act (EEA) 55 of 1998 (Republic of South Africa, 1998), South Africa is not meeting the target of two percent of persons with disabilities in all sectors of open labour employment in the country. The public and private sector need to implement disability management (DM) policies and procedures to ensure that persons with disability (PWD) or persons with ill-health are managed appropriately through reasonable accommodation to achieve the target of 2\% mandated by the Employment Equity Act (Republic of South Africa, 1998). Employees with disabilities can make a positive contribution in the workplace provided there is implementation of appropriate DM strategies in the workplace. Unfortunately, PWDs seen as a problem rather than an asset within the workplace (Baker-McClearn et al., 2010; Maja, Mann, Sing, Steyn, \& Naidoo, 2011; Public Service Commission, 2008; Paykel \& Priest, 1992).

Employer's practices and attitudes towards PWDs within the workplace have a significant impact on successful return to work (RTW). The process of RTW following long-term sick leave remains a challenge within the public sector in South Africa (Whitaker, 2001; Olivier, 2012). At the employer level, long-term sickness absence leads to lower productivity, higher employee turnover and reduction in job satisfaction due to the added workload placed on other employees in the department (Whitaker, 2001; Baker-McClearn et al., 2010; Munir et al., 2008). Successful RTW minimises the cost of disability for the employer and enables the employee to remain at work or RTW in a timely manner (Whitaker, 2001; Olivier, 2012).

The World Health Organisation (WHO) defines $\mathrm{OH}$ as a multidisciplinary activity aiming at protecting and promoting health of workers through preventing and controlling occupational diseases and accidents and reducing occupational factors and hazardous conditions in the work place (WHO, 2002). Furthermore, occupational health is the development and promotion of physical, mental and social well-being of workers for the maintenance of their work capacity and professional and social development at work (World Health Organisation (WHO, 1995). A well-managed $\mathrm{OH}$ service helps to reduce the use of excessive sick leave and absenteeism and promotes employee's morale, and provides onsite care (Whitaker, 2001; Department of Health, 2003). Counselling helps to promote job satisfaction thereby reducing staff turnover.

Health care workers are vulnerable to infections and prone to developing musculoskeletal injuries, primarily from incorrect manual lifting of patients. Chronic diseases such as osteoarthritis, diabetes, hypertension, heart conditions, and degenerative diseases of the spine are the common conditions that affect the ageing health-care worker resulting in long-term absence from work and in decreased productivity in the workplace (Department of health, 2003; Whitaker, 2001). Mental conditions such as major depression reduces work productivity and can occur at any age. Gold \& Shuman's (2009) study reported the mean onset age for depression as 25.8 years. The mean age for South Africans is 26 years old and women are more tend to have more sickness absenteeism than men do (Gold \& Shuman, 2009). Depressive disorders are often unrecognised and untreated and cause distress and disability (Gold \& Shuman, 2009; Ramano, 2011). Occupational therapists (OT) plays a significant role in mental health and physical health in terms of assessment and rehabilitation as the OT focuses on functional performance 
and capacity to work with the goal of intervention moving towards promotion of a sense of self -esteem and self-efficacy within the individual (Ramano, 2011). Policy and legislation indicate that although it is not compulsory, it is imperative for employees to disclose their disability status to their managers or to relevant persons designated to handle such matters (Ramano, 2011) Disclosure enables the disabled employee to be reasonably accommodated (Republic of South Africa, 2005).

A DM programme is a process in the workplace designed to enable the employment of PWDs in a co-ordinated effort considering the individual needs, organisation needs and the legal responsibilities (Department of Public Service and Administration, 2006). An integrated DM approach has many advantages such as enhanced communication between employer and employee, improved cost efficiency through decreases duplication of services and increased capacity to measure health and productivity (Angeloni, 2013). An effective DM system reduces long-term absenteeism and employee turnover in terms of medical boarding or early retirement as the result of ill health. DM improves productivity, employee satisfaction, health and safety outcomes by providing services that are employee centred (Angeloni, 2013; Krause \& Lund, 2004). Return to work strategies and reasonable accommodation (RA) are essential aspects in DM. A successful RTW system decreases absenteeism rates and enables an ill or a disabled employee to secure, retain or advance in suitable employment within the current workplace thereby reintegrating employees back into the open labour market and decreasing the burden on the state in terms of disability pensions or incapacity pay-outs (Angeloni, 2013; Gensby et al., 2012; Naidoo et al., 2016). Reasonable accommodation is defined as measures taken to ensure that a person with disability is able perform duties with minimal assistance through provision of assistive devices, rearranging working hours, reassigning duties and making the premises accessible (Schreuer, Myhill, Aratan-Bergman, Samant \& Blanck, 2009; Department of Public Service and Administration, 2007; Naidoo et al., 2016). Reasonable Accommodation is not universal and is aligned to an individual employee's needs. Schreur et al's (2009) study highlighted that reasonable accommodations can enable persons with disabilities to perform their jobs, and maintain successful employment. Occupational therapists have a vital role to play in DM and in enhancing workforce management Coetzee, Goliath, van der Westhuizen \& Van Niekerk, 2011; Ostiguy, 2010). In Canada, OTs are called upon to arrange for workplace accommodation for all types of workers making the most of their occupational performance on the job (Ostiguy, 2010). Vocational rehabilitation services offered by OT in the public sector in SA comprises of prevention, assessment, intervention, placement and early intervention for injured employees or employees suffering from ill health to return to optimal health (Van Biljon, Casteljien, du Toit \& Soulsby, 2006). Occupational therapists need to work with the employers and employees to plan and implement RTW strategies by conducting evaluations of the workplace and work ability in response to job descriptions and tailor RTW strategies to the individual's needs (Coetzee et al., 2011).

The $\mathrm{OH}$ clinic policy of the KwaZulu Natal (KZN) health care facility, were the study was conducted, allows only the employees of the public sector to access the institution's OH services. The OT department at this facility has been providing vocational assessments for employees with ill health or disabilities since 2005 . The $\mathrm{OH}$ clinic referred 23 employees, over a period of 10 years (2005-2015) to OT for vocational assessments. The employees referred had experienced difficulties with their work demands as the result of work related illness, ill health, impairments or acquired disabilities and were absent from work for extended periods. These employees had additionally exhausted their ill health incapacity leave. This paper describes the profile of employees with ill health or disabilities and explores the perceptions of employees with regard to return to work strategies that were implemented at this KZN private public health care facility following vocational assessments by the occupational therapists.

\section{Method}

\subsection{Research Design}

A case study design was used to profile the disability management strategies implemented at a KwaZulu-Natal central quaternary health care facility. This design was suitable as it offered means to explore the phenomena of return to work strategies in more depth at the study location though the use of multiples sources of data (Yin, 2014).

\subsection{Sampling}

All employees with disabilities or ill health who had undergone work assessments by the occupational therapists for the period of 2005-2015 were selected for inclusion in the study $(n=23)$ via saturation sampling. The employee's details were documented via a file audit. All employees were selected for semi-structured telephonic interviews, however only 17 out of the 23 identified employees were included. Six employees were inaccessible for the interviews; one had demised and five had incorrect contact details and was no longer in the employ of the 
facility.

\subsection{Data Collection Methods}

Data collection methods, in this single site case study, included a file audit, a Work Ability Index (WAI) assessment (Ilmarinen, 2003) and semi-structured interviews with employees. A file audit was undertaken. Data were extracted from the electronic medical records and occupational therapy assessment reports using a data-extracting tool. The categories in the data extraction tool included demographics, diagnosis, occupational class, treatment interventions, assessments utilised and occupational therapy recommendations. The WAI was administered individually to determine the current work ability status of the employees. Employees were contacted telephonically to ascertain their current work ability and functional capacity. The WAI tool is a quick and easy tool and reveals an overall assessment of a worker's ability and functional capacity (Ilmarinen, 2003). The WAI tool consists of a seven-part self-assessment focusing on current ability, work ability in relation to physical and mental demands of the job, reported diagnosed diseases, estimated impairment due health status and sick leave over a period of 12 months, and a self-prognosis of work ability. The rating has four categories, namely a score of 7-27 is poor, 28-36 -moderate, 37-43-good and 44-49 excellent. The score obtained from the tool is used to promote, maintain work ability and follow up on employees who should cope with disability and illness at work (Ilmarinen, 2003). The WAI was piloted on an employee with disabilities who was not employed at the hospital to ensure accuracy of data for this study. Seventeen 20-minute telephonic semi-structured interview were conducted with employees. The interview schedule focused on impact of illness on their work ability, their experience of return to work, factors that hinder or facilitate employees early RTW and following up on whether the recommendations from the occupational therapy assessment had been implemented. The schedule of questions for the semi-structured interviews was piloted to ensure that questions were clear and unambiguous. Informed consent was obtained from all employees prior to the interview.

\subsection{Ethical Considerations}

Ethical approval was obtained from the University of KwaZulu-Natal Humanities and Social Sciences Ethics Committee (HSS/0168/016) prior to the commencement of this study. Ethical clearance was also obtained from KZN Department of Health (HRKM77/16). Gatekeeper permission from the healthcare institution was granted to carry out the study and to peruse client records. Participation in the study was voluntary and participants were informed that they could withdraw from the study with no negative consequences. Written informed consent was obtained from all employees. Confidentiality and anonymity was maintained through allocating each participant a number as an identifier. Data collected was stored in a controlled access in a safe location.

\subsection{Data Analysis}

Data extracted from the file audit was analysed using Microsoft excel. Descriptive statistical analysis utilising frequencies and percentages was used to describe demographics, diagnosis, occupational class, treatment interventions, occupational therapy assessments and occupational therapy recommendations from the file audit. Scores from the Work ability index tool were computed electronically and a rating of the employees work ability was attained. Qualitative data from the semi-structured interviews were analysed thematically (Braun \& Clarke, 2006). The audio-recorded semi-structured interviews were transcribed verbatim. The transcripts were initially coding in the margin of the transcript (level 1 analysis), followed by categorisation of similar codes under a common category (level 2 analysis). This was followed by pattern matching to identify themes (Braun \& Clarke, 2006).

\section{Results}

Twenty-three files (medical records and occupational therapy files) were accessed over a ten-year period. The characteristics of the study participants are described in Table 1. 
Table 1. Characteristics of Study Participants $(n=23)$

\begin{tabular}{|c|c|c|c|}
\hline Category & & Frequency & Percentage \\
\hline \multirow{2}{*}{ Gender } & Males & 2 & $9 \%$ \\
\hline & Females & 21 & $91 \%$ \\
\hline \multirow{4}{*}{ Age at Assessment } & $21-30$ & 1 & $4 \%$ \\
\hline & $31-40$ & 8 & $35 \%$ \\
\hline & $41-50$ & 11 & $48 \%$ \\
\hline & $51-65$ & 3 & $13 \%$ \\
\hline \multirow{3}{*}{ Level of Secondary Education } & Grade 12 & 22 & $96 \%$ \\
\hline & Grade 11 & 0 & $0 \%$ \\
\hline & Grade 10 & 1 & $4 \%$ \\
\hline \multirow{2}{*}{ Level of Tertiary Education } & Undergraduate Degree & 7 & $30 \%$ \\
\hline & Diploma & 16 & $70 \%$ \\
\hline \multirow{6}{*}{ Occupational Class } & Nurses & 16 & $70 \%$ \\
\hline & Clinical Technologist & 2 & $9 \%$ \\
\hline & Medical Doctor & 1 & $4 \%$ \\
\hline & Pharmacy Assistant & 1 & $4 \%$ \\
\hline & Phlebotomist & 1 & $4 \%$ \\
\hline & Social Worker & 1 & $4 \%$ \\
\hline
\end{tabular}

\subsection{Diagnostic Categories}

All twenty-three employees had multiple diagnoses. The diagnostic categories included orthopaedic conditions (61\%), neurological impairments (52\%), degenerative spinal disease (35\%), cervical spondylosis $(39 \%)$ and lumbar spondylosis (30\%). Employees also presented with mechanical backache (22\%), osteoarthritis of knee $(30 \%)$ and depression $(30 \%)$.

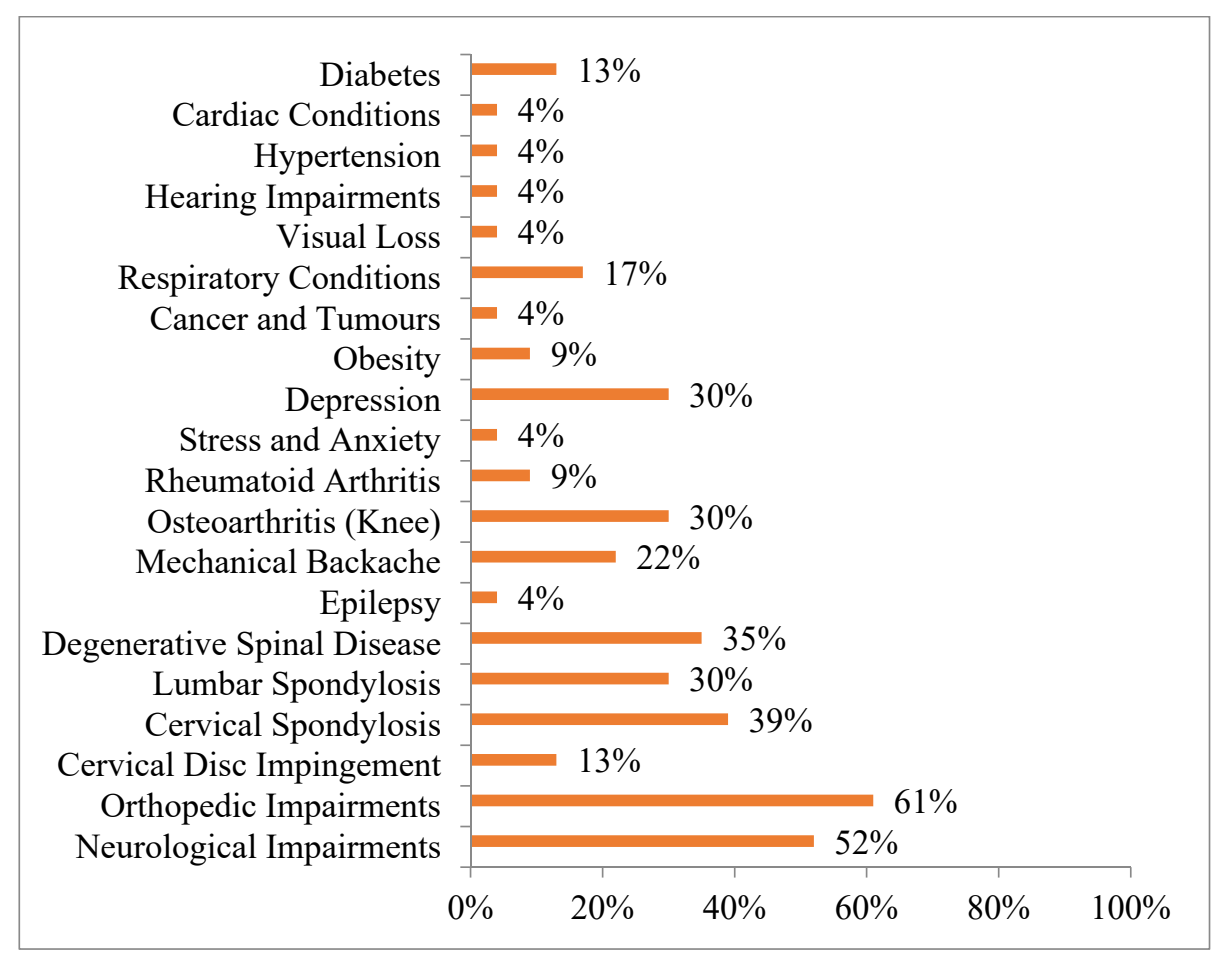

Figure 1. Diagnostic Categories $(n=23)$ 


\subsection{Work Ability Index (WAI) and Functional Status of the Employees}

Of the 23 employees, $74 \%(n=17)$ participated in the administration of the work ability index. Rating scores ranged from poor to excellent as described in Table 2 .

Table 2. Work Ability Index

\section{WORK ABILITY INDEX}

\begin{tabular}{llll}
\hline Score & Rating & \% of Employees & Description \\
\hline $7-27$ & Poor & $21.7 \%$ & Work ability needs to be restored \\
\hline $28-36$ & Moderate & $56.3 \%$ & Moderate functioning. Employer is required to improve work ability \\
\hline $37-43$ & Good & $0 \%$ & Employer should support employee \\
\hline
\end{tabular}

\subsection{Current Employment Status of Employees}

On the 23 employees who were assessed only $78 \%(n=18)$ participated in the work ability profile. The $22 \%(n=5)$ who did not respond had either been resigned, transferred, sought alternate employment, or dismissed. A total of $56 \%$ $(n=13)$ of the participants are currently employed at the institution, scored between 28 and 38 on the WAI, rating their work performance as moderate. These participants required some form of reasonable accommodation. None of the participants scored their work ability as good. Of these, $22 \%(n=5)$ employees scored $7-9$ on the work ability profile and are therefore medically boarded or on long-term incapacity leave.

\subsection{Investigations and Interventions}

All $(100 \% ; n=23)$ employees, had a series of tests and investigations to confirm their respective diagnosis. Various medical and, rehabilitation interventions were offered to assist in improving the impact of the diagnosis on the employee's work ability (Figure 2).

\subsection{Occupational Therapy Assessments: Formal and Informal Assessments}

A variety of formal and informal vocational tests and assessments were utilised by the occupational therapists in the vocational assessment reports. The most common methods of assessment included perusal of medical records, interviews, physical and functional assessments, formal assessments such as the COTNAB and self-reporting surveys such as the Work Ability Profile or the McGill Pain Questionnaire. The assessment tools selected depended on the complexity of the diagnosis and the areas of occupational performance that the therapist was required to assess.

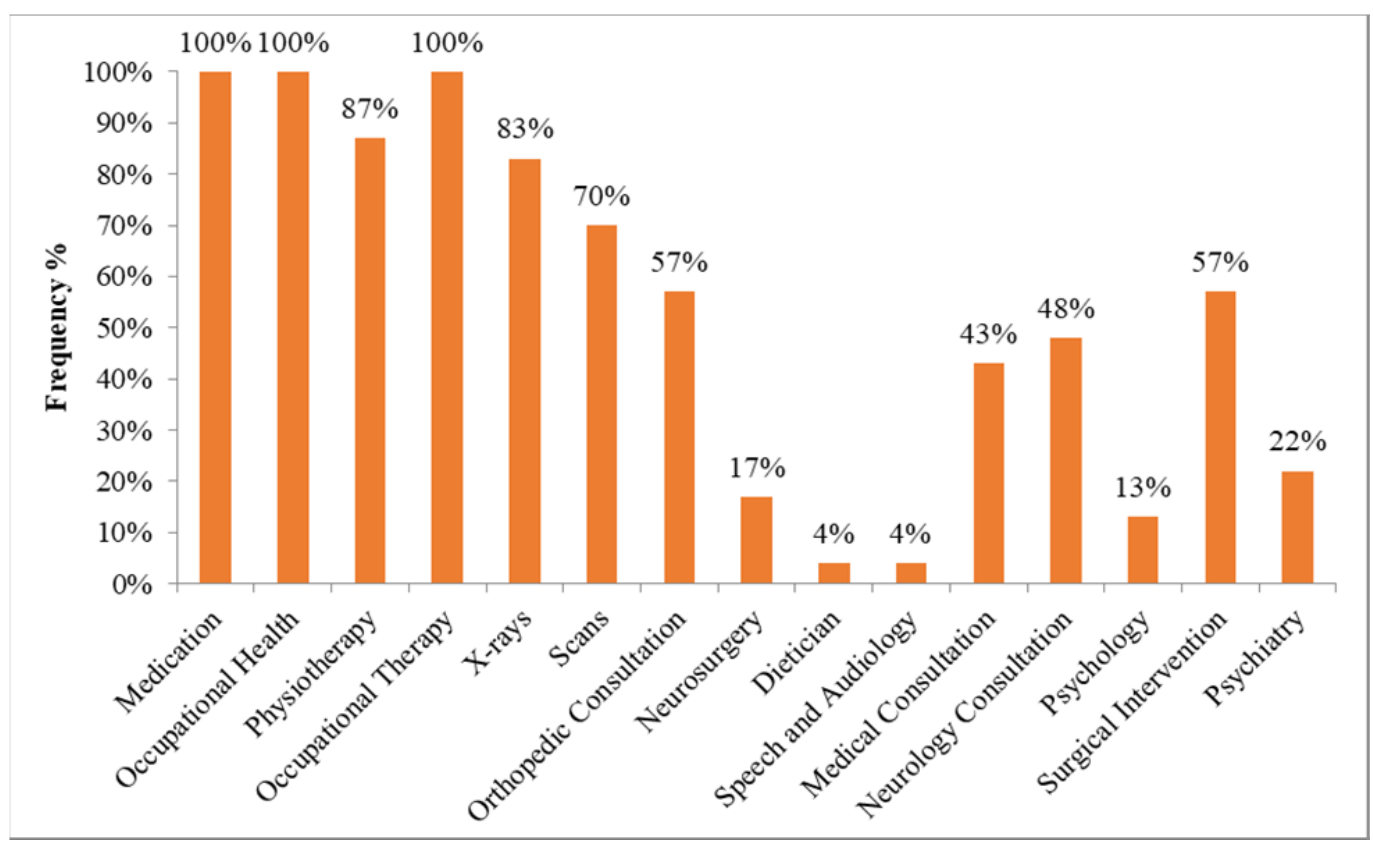

Figure 2. Investigations and Interventions $(\mathrm{n}=23)$ 


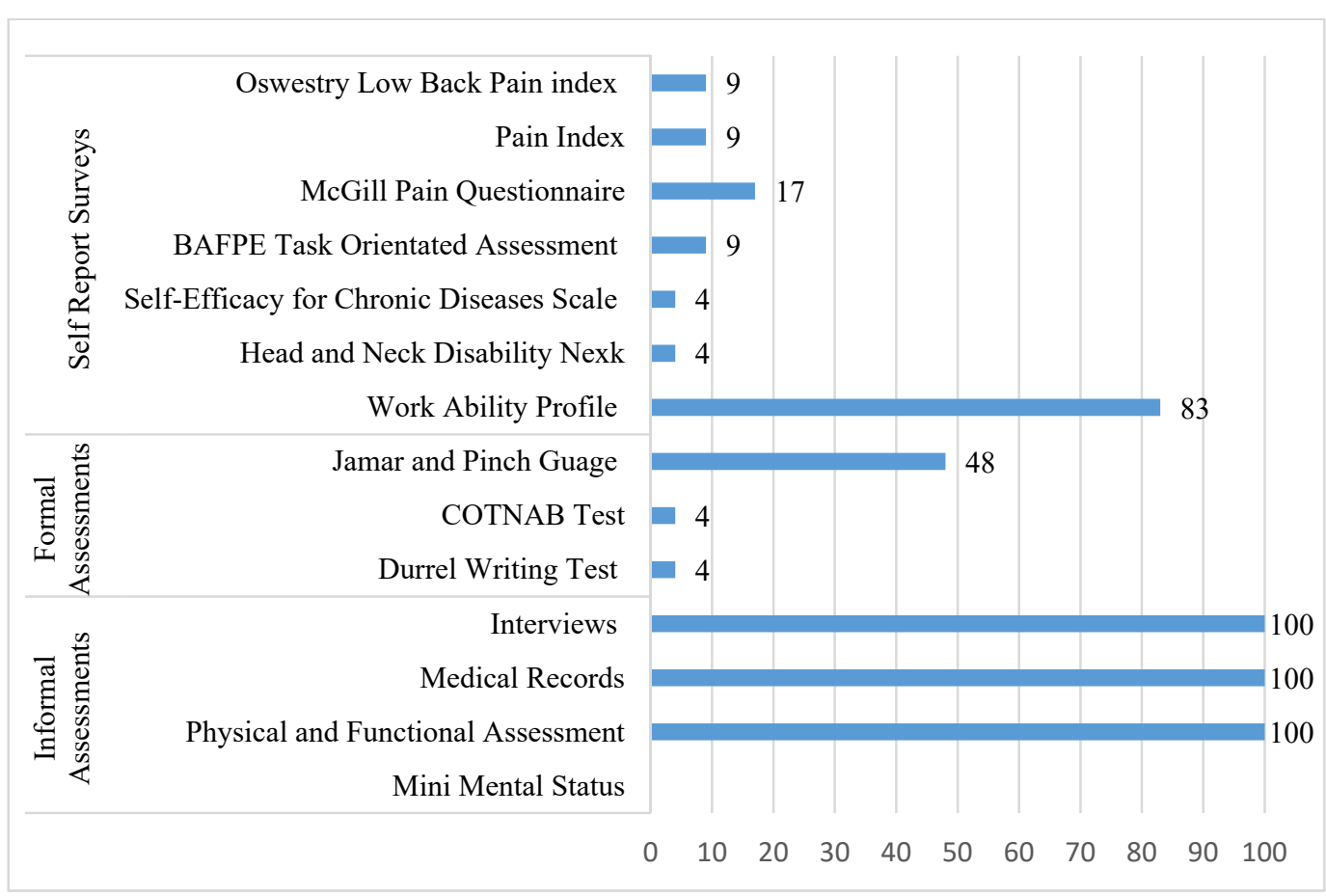

Figure 3. Formal and informal occupational therapy assessments $(n=23)$

\subsection{Recommendations}

Realignment of duties including light duty, and modification of existing duties were recommended for $74 \%$ of employees. Further rehabilitation were suggested for $61 \%$ of employees and this included physiotherapy, occupational therapy and/or speech therapy. Other recommendations included medical intervention (4\%), psychosocial support (30\%) and support from colleagues (4\%). Flexible work schedules (30\%), improved working conditions (4\%), energy conservation techniques (30\%) and application of ergonomics (35\%) were also endorsed. Assistive devices or surgical appliances (35\%) comprising an electric wheelchair, lumbar sacral corsets, neck collar, splint or mobility device such as walking stick or walker were suggested. Medical boarding was initially recommended for $13 \%$ of employees, as they were permanently disabled and unable to return to work. This later increased to $22 \%$ as the employees were unable to be rehabilitated.

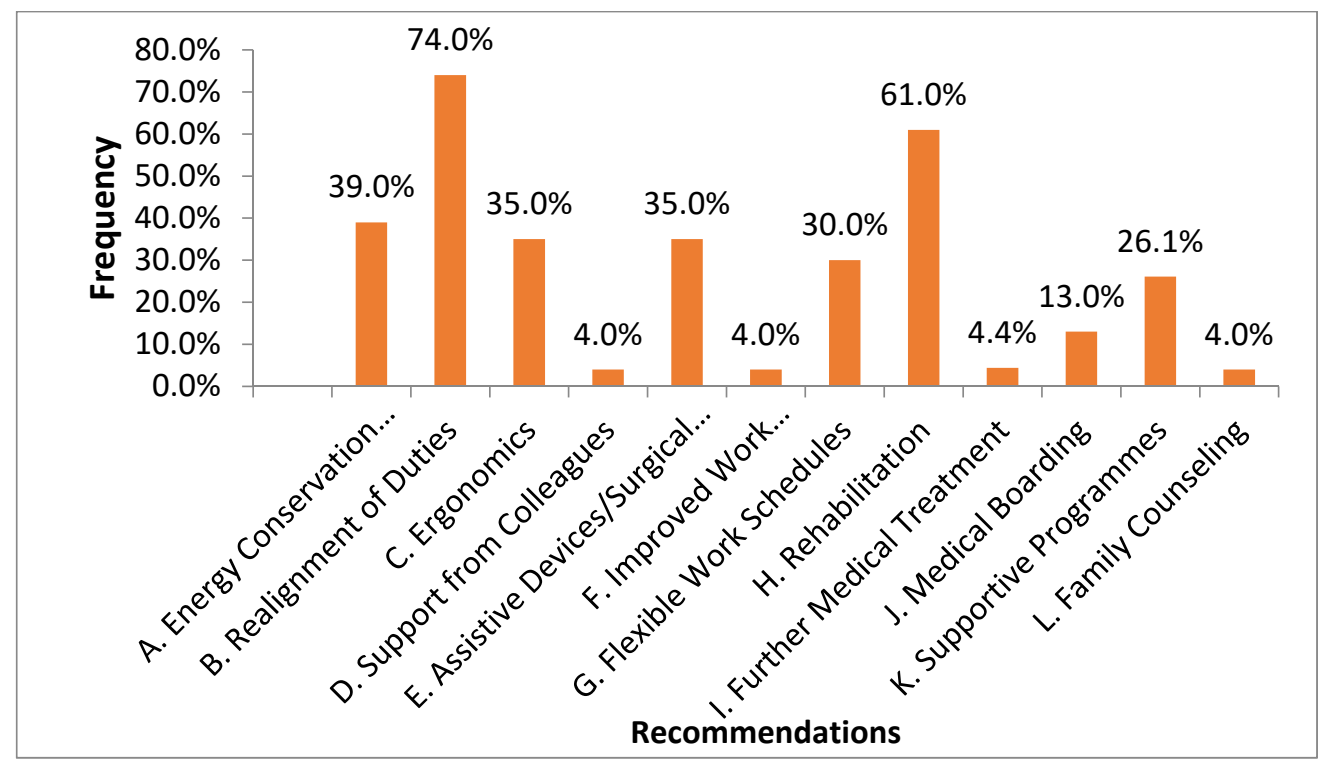

Figure 4. Recommendations made by the OT for the Employee ( $\mathrm{n}=23$ ) 


\subsection{Results of the Semi-Structured Interviews}

Two major themes emerged from the semi-structured interviews namely factors that enabled successful RTW and factors that hindered successful RTW. The relevant quotes are highlighted under each theme to reflect the authentic voice of the employees.

\subsubsection{Factors That Enabled Successful RTW}

The employees reported the factors that facilitated return to work included job realignment in terms of light duties; reallocation to clinics and flexible work schedules i.e. being allowed to work straight shifts. Additionally having supportive co-workers and supportive and accommodating supervisors; teamwork and good communication between manager and employee. Furthermore the employee's positive attitude and the will power to RTW following illness or disability were facilitators for RTW. Supportive families were found to assist in the early recovery and RTW process. Employees found that they were more encouraged to RTW when their disability or illnesses were well- controlled.

\section{"Determination and support from my family and most importantly my children."(Employee 1)}

"The OT plays a role in ongoing assessments, recommendations and feedback and the provision of assistive devices." (Employee 12)

Access to reasonable accommodation measures, assistive devices and surgical appliances such as electronic wheelchairs, lumbar corsets, and neck collars facilitated successful early RTW. The employees also emphasised the need for a structured referral system and policy injured or ill employees to access $\mathrm{OH}$ and DM within the workplace. Employees reported that DM is important as the knowledge of a structured system in place concerning handling staff with disabilities or partial disability in the workplace would empower people to access this service. All employees agreed that the OT plays a significant role in terms of assessments, recommendations, feedback and provision of assistive devices but the employees noted that not all recommendations are implemented.

"I think the modifications of my work environment were largely due to me being forceful" (Employee 1)

"DM is important it will empower people it there was a structured system in place with regards to handling staff with disabilities or partial disability in the workplace". (Employee 5)

\subsubsection{Barriers and Challenges That Hindered Successful RTW}

The employees reported that there is extensive "red tape" within the health care institute preventing an employee from moving from one domain to the other unless there are promotional posts available, resulting in financial implications. Lack of formal referral policies and procedures concerning DM and ill health within the facility also hinders RTW. Lack of information as well as poor communication from human resources about documentation submitted for long-term incapacity leave or medical board requests, remains a challenge. Employees reported that the process for medical boarding within the public health care facility is long and tedious. Employees experience financial constraints, once sick leave and long-term incapacity leave are exhausted. Employees reported factors such as unsupportive supervisors, negative attitudes of co-workers, and lack of teamwork as negatively influencing RTW. The unavailability of light duties or other job realignment opportunities, inflexible work schedules and lack of reasonable accommodation measures hinders early RTW. Employees reported rigid job descriptions and an emphasis on inabilities and rather than abilities as being problematic in disability management. Furthermore, there is a lack of access to on-going rehabilitation opportunities within the public health care facility. There is an increase in frustration and depression as the ill employee is not able to function as efficiently as they used to. Lack of funding and accessibility to appropriate assistive devices also negatively influence reasonable accommodation initiatives. The fear of victimization remained a concern when disclosing an illness or disability.

"In terms of allocations to wards, it is still the same, there was no flexibility in terms of changing my responsibilities and job description." (Employee 1)

"Colleagues attitudes and behaviour appalling, disappointing, heart breaking I used to go home and cry daily no empathy what so ever" (Employee 1)

"People don't understand what the processes are and what their rights are you know, it's brushed under the carpet." (Employee 8)

"Lack of job realignment opportunities, I could only move when I applied for a promotion. "(Employee 17).

\section{Discussion}

This study aimed at exploring the RTW strategies adopted following ill health in a KZN public-private health care facility. The core occupational class assessed were nurses such as enrolled nursing assistants, professional nurses 
and chief professional nurses. Common diagnoses included orthopaedic conditions and depression. All employees had multiple diagnoses which is in keeping with other studies indicating that the aging health care workers are more prone to ergonomic hazards, which includes lifting, overexertion and repetitive motion of transferring patients (Alavinia, van den Berg, van Duivenbooden, Elder \& Burdorf, 2009). Health care workers especially the nursing staff are prone to many workplace hazards such as overburden of large workloads, staff shortages, long working hours, extensive paperwork. Nurses encounter severe stress working in specialised areas such as trauma and ICUS, resulting in stress, anxiety and depression (Lekgothoane, 2012), which is congruent with findings in this study. Thirty percent of the employees were diagnosed with depression. Depressive disorders are often unrecognised and untreated causing distress and disability (Gold \& Shuman, 2009; Kim, Kim, Lee, Yook, Hong, Lee, et al., 2018).

The findings in the study supported the role of OT in the disability management process, with participants stating that OTs provided assistance with assessments, reasonable accommodation and assistive devices. Similarly, some studies have recognised OT assessment and intervention to improve the return to work rate for employees with both mental health and orthopaedic conditions (Ostiguy, 2010; Coetzee et al., 2011). Additionally, the OTs role in the provision of appropriate assistive devices such as wheelchairs and mobility devices, supports and splints, is acknowledged. Furthermore, OTs facilitate vocational rehabilitation, which entails worksite assessments, advice to employers about reasonable accommodation, and rehabilitation of employees with disabilities or illness (Ostiguy, 2010). The goals of OT in vocational rehabilitation are to prevent potential disability, returning employees into gainful employment and keeping employees with ill health gainfully employed (Gottlieb, Myhill, \& Blanck, 2010) Ergonomics plays a fundamental role increasing the social and work participation of PWDs (Gottlieb, Myhill \& Blanck, 2010). Ergonomics, provision of assistive devices, RA are essential components of vocational rehabilitation, which facilitates reintegration and early RTW, therefore OTs, have the necessary skills to be a key role player in DM (Ostiguy, 2010; Gottlieb et al., 2010).

The results obtained from the file audit of 23 files indicates that majority of employees assessed were females and $48 \%$ of the age group ranged between 41-50 years which is in keeping with the World Health Organisation disability report which stated disabilities are higher in females (World Health Organisation, 2011). Ill health and disabilities are more prevalent in an aging workforce, which is in keeping with the study (Nicholas \& Sharp, 2016). The health care profession is a female dominated profession and women tend to have more sickness absence than men do (Naidoo et al., 2016). The $\mathrm{OH}$ clinic referred employees to occupational therapy for vocational assessments, the therapists utilised a variety of tests depending on the medical condition to ascertain the status of the employees. Common methods included perusal of medical records, interviews, work ability profile and physical and functional assessments. OT recommendations included reasonable accommodations such as job realignment, improvement of workplace ergonomics and further rehabilitation. These recommendations were supposed to be implemented by the supervisors however employees reported that these recommendations were frequently not implemented, hindering successful RTW. Employees reported that negative co-workers and supervisors attitudes hindered RTW following ill-health or disability.

Employees reported there are a number of challenges with implementation of the DM policy. In this study participants with a low work ability index score of 7-9 are either medically boarded or on long-term incapacity leave. However, participants who scored moderate (28-38), are currently employed within the institution but require job realignments and reasonable accommodation. The Code of Good Practice on the Employment of PWD states that the employer is required to implement these strategies to facilitate successful RTW, and RA thereby decreasing long-term sick leave and absenteeism within the workplace and improving productivity in the workplace (Republic of South Africa, 2002). Contrary to this Code, participants reported factors hindering RTW which included not knowing the processes for disability management deteriorating medical condition, lack of realignment opportunities, poor access to assistive devices, unsupportive colleagues and manager and the lack of policies and procedures. It was evident from the study that specific disability management policies and procedures are lacking, and formal policy on RTW programmes are required in the institution. Majola \& Dhunpath (2016) collaborates this by reporting that due to the lack of disability specific policies in the public sector, 20 years' post democracy, employees who are disabled are deprived of their constitutional rights and KZN is not meeting its $2 \%$ employment target. It is essential to have an internal referral and monitoring process of employees who are disabled or ill as this would decrease the abuse of sick leave and facilitate access to the ill health retirement process for those with progressive medical conditions. Furthermore, an integrated disability management programme will certainly facilitate early RTW and increase productivity in the public health care facility. 


\section{Conclusion}

This study concludes that employees with ill-health and disabilities within public health care facilities face several challenges and barriers regarding early RTW. The challenges included the unavailability of light duties or other job realignment opportunities, inflexible work schedules and lack of implementation of RA measures. Furthermore, employees reported rigid job descriptions, an emphasis on inabilities and a lack of access to on-going rehabilitation opportunities within the public health care facility which hindered the RTW process. However, some of employees reported that the implementation of reasonable accommodation measures and having a supportive supervisor, who communicates well with his/her employee, were enabling factors in the RTW process. Additionally, this study highlights the essential role OTs play in DM through vocational assessments, rehabilitation and reintegration programmes. The findings from this study stressed the need for an integrated disability management policy, procedures and programmes to be established within public health care facilities to monitor employees with ill-health and disabilities and to support their RTW process.

\section{Competing Interests Statement}

The authors declare that there are no competing or potential conflicts of interest.

\section{References}

Alavinia, S. M., van den Berg, T. I. J., van Duivenbooden, J. C., Elders, L. A. M., \& Burdorf, A. (2009). Impact of work-related factors, lifestyle, and work ability on sickness absence among Dutch construction workers. Scand J Work Environ Health, 35(5), 325-333. https://doi.org/10.5271/sjweh.1340

Angeloni, S. (2013). Integrated disability management: An interdisciplinary and holistic approach. SAGE Open, 3(4). https://doi.org/10.1177/2158244013510303

Baker-McClearn, D., Greasley, K., Dale, J., \& Griffith, F. (2010) Absence management and presentism: The pressures on employees to attend work and the impact of attendance on performance. Human Resource Management Journal, 20(3), 311-28. https://doi.org/10.1111/j.1748-8583.2009.00118.x

Braun, V., \& Clarke, V. (2006). Using thematic analysis in psychology. Qualitative Research in Psychology, 3(2), 77-101. https://doi.org/10.1191/1478088706qp063oa

Burger van Eeden, M., \& Jordan, B. (2008). A cure for sick leave abuse (pp. 10-5). HR management, USB Leaders Lab.

Coetzee, Z., Goliath, C., van der Westhuizen, R., \& Van Niekerk, L. (2011). Re-conceptualising vocational rehabilitation services towards an inter-sectoral model. South African Journal of Occupational Therapy: 41(2), 32.

Department of Health. (2003). Occupational Health Services for health care workers in the National Health Service of SA, Guideline booklet (pp. 1-72). Department of Health.

Department of Public Service and Administration. (2005). Policy and procedure on incapacity leave and ill health retirement.

Department of Public Service and Administration. (2006). Job access strategic framework on the recruitment, employment and retention of persons with disabilities in the public service. Department of Public Service and Administration, Pretoria Government printer.

Department of Public Service and Administration. (2007). Handbook on reasonable accommodation for people with disabilities in the public service. Department of Public Service and Administration, Pretoria Government Gazette.

Gensby, U., Lund, T., Kowalski, K., Saidj, M., Jørgensen, A. M. K., Filges, T., \& Labriola, M. (2012). Workplace disability management programs promoting return to work: A systematic review. Campbell Systematic Reviews, 8(17). https://doi.org/10.4073/csr.2012.17

Gold, L. H., \& Shuman, D. W. (2009). Evaluating mental health disability in the workplace: Model, process and analysis. Springer Science and Business Media LLC.

Gottlieb, A., Myhill, W. N., \& Blanck, P. (2010). Employment of people with disabilities. International Encyclopedia of Rehabilitation. Center for International Rehabilitation Research Information.

Grobler, C., \& Lapere, J. (2016). Sick leave and work absence part 1: can sick leave be harmful to patients?: back to basics. Occupational Health Southern Africa, 22(3), 17-9.

Ilmarinen, J. (2003). Work ability index: A tool for occupational health research and practice. Finish Institute of 
Occupational Health.

Kim, M. S., Kim, T., Lee, D., Yook, J. H., Hong, Y. C., Lee, S. Y., \& Kang, M. Y. (2018). Mental disorders among workers in the healthcare industry: 2014 national health insurance data. Annals of occupational and environmental medicine, 30(1), 31. https://doi.org/10.1186/s40557-018-0244-x

Krause, N., \& Lund, T. (2004). Returning to work after occupational injury. The psychology of workplace safety (265-95). Washington DC: American Psychology Association Books. https://doi.org/10.1037/10662-013

Lekgothoane, A. M. (2012). Occupational injuries and diseases amongst healthcare workers of the department of health in Limpopo Province (Doctoral dissertation, University of Limpopo (Medunsa Campus)).

Maja, P. A., Mann, W. M., Sing, D., Steyn, A. J., \& Naidoo, P. (2011). Employing people with disabilities in South Africa. South African Journal of Occupational Therapy, 41(1), 24-32.

Majola, B. K., \& Dhunpath, R. (2016). The development of disability-related employment policies in the South African public service. Problems and Perspectives in Management, 14(1). https://doi.org/10.21511/ppm.14(1-1).2016.02

Mayosi, B. M., Flisher, A. J., Lalloo, U. G., Sitas, F., Tollman, S. M., \& Bradshaw, D. (2009). The burden of non-communicable diseases in South Africa. Lancet, 374(9693), 934-47. https://doi.org/10.1016/S0140-6736 (09)61087-4

Munir, F., Yarker, J., \& Haslam, C. (2008) Sickness absence management: encouraging attendance or 'risk-taking' presenteeism in employees with chronic illness? Disability and Rehabilitation, 30(19), 1461-72. https://doi.org/10.1080/09638280701637380

Naidoo, R. N., Naidoo, S., \& Hariparsad, S. (2016). Disabling health: the challenge of incapacity leave and sickness absence management in the public health sector in KwaZulu-Natal Province. South African Health Review, 1, 61-72.

Olivier, M. (2012). Return-to-work and Disability Management in the developing world: Developments in South Africa and Malaysia, with reference to the UN Convention on the Rights of Persons with Disabilities and comparative precedents (Doctoral dissertation, Faculty of Law, Nelson Mandela Metropolitan University Port Elizabeth).

Ostiguy, E. (2010). Occupational Therapy Solutions to Common Workplace Issues: A Manual to Enhance Workforce Management (pp. 1-14). CAOT Publications: ACE, Ottawa, Ontario.

Public Service Commission. (2008). Assessment on Disability Equity in the Public.

Ramano, E. M. (2011). Perceptions and practices of occupational therapists in determining work capacity of employees suffering from a depressive disorder. (Doctoral Dissertation. University of Pretoria).

Republic of South Africa. (2002). Code of Good Practice on Employment of People with Disabilities. Retrieved from http//www.labour.gov.za/legislation/code

Republic of South Africa. (2005). Technical Assistance Guidelines on the Employment of People with Disabilities. Retrieved from http://www.labour.gov.za/useful-docs

Republic of South Africa. Employment Equity Act, No. 55 of 1998. Government Gazette. 1998; 400 (19370). Retrieved from http://www.labour.gov.za/DOL/downloads/legislation/acts/employmentequity/eegazette2015.pdf

Schreuer, N., Myhill, W. N., Aratan-Bergman, T., Samant, D., \& Blanck, P. (2009). Workplace accommodation: Occupational Therapists as mediators in the interactive process. Work, 34(2), 149-160.

Shreuder, J. A. (2012). Managing sickness absence, leadership and sickness absence behavior in hospital care (Doctoral dissertation, University of Groningen, Netherlands).

van Biljon H. M., Casteljien, D., du Toit, S. H., \& Soulsby, L. (2006). Opinions of occupational therapists on the positioning of vocational services in Gauteng Public Healthcare. South African Journal of Occupational Therapy, 46(1), 42-52. https://doi.org/10.17159/2310-3833/2016/v46n1a10

Whitaker, S. C. (2001). The management of sickness absence. Occupational and Environmental Medicine, 58(6), 420-4. https://doi.org/10.1136/oem.58.6.420

Work ability online tool, WAI Network. $\quad$ Retrieved from http://www.arbeitsfaehigkeit.uni-wuppertal.de/index.php?wai-online-en 
World Health Organization [WHO]. (1995). Global strategy on occupational health for all: the way to health at work, recommendation of the Second Meeting of the WHO Collaborating Centres in Occupational Health, 11-14 October 1994, Beijing, China (No. WHO/OCH/95.1. Unpublished). Geneva: World Health Organization. $\quad$ Retrieved $20 \quad$ May, 2019 , from https://www.who.int/occupational_health/publications/globstrategy/en/index5.html

World Health Organization [WHO]. (2002). Occupational health: a manual for primary health care workers (No. WHO-EM/OCH/85/E/L). World Health Organization. Regional Office for the Eastern Mediterranean.

World Health Organization [WHO]. (2011). World report on disability 2011. https://doi.org/10.30875/b51b2f2c-en Yin, R. K. (2014). Case study research: Design and methods. Thousand Oaks. SAGE Publications.

\section{Copyrights}

Copyright for this article is retained by the author(s), with first publication rights granted to the journal.

This is an open-access article distributed under the terms and conditions of the Creative Commons Attribution license (http://creativecommons.org/licenses/by/4.0/). 